\section{Proteinuric renal}

\section{disease}

Peter Topham, Senior Lecturer in

Nephrology; Honorary Consultant

Nephrologist, John Walls Renal Unit,

University Hospitals of Leicester

Proteinuria is a cardinal feature of renal disease and an important clinical finding

because it:

- $\quad$ is a marker for the presence of renal disease

- mediates progressive renal dysfunction, and ${ }^{1,2}$

- $\quad$ is an independent and powerful risk factor for the development of cardiovascular disease. ${ }^{3}$

This review will focus on the causes of proteinuria, the approach to evaluating patients with proteinuria and general management principles for proteinuric patients.

\section{Normal urine protein composition}

Under normal conditions the low molecular weight proteins and albumin that are filtered from plasma into the early tubular fluid are almost completely reabsorbed in the proximal tubules. This results in a normal daily urinary protein excretion of less than $150 \mathrm{mg}$, of which only approximately $10 \mathrm{mg}$ is albumin. More than $150 \mathrm{mg}$ of proteinuria per day is regarded as abnormal, although it is now appreciated that early renal disease (particularly in diabetic patients) is associated with low level albuminuria (30-300 mg per day) (ie microalbuminuria). An increase in proteinuria can be identified in a number of clinical contexts.

\section{Types of proteinuria}

\section{'Functional' proteinuria}

Transient subnephrotic proteinuria, 'functional proteinuria', can occur following exercise or in association with fever or heart failure. It is benign and probably mediated by glomerular haemodynamic changes. ${ }^{4}$

\section{Overflow proteinuria}

Overflow proteinuria is caused by the increased filtration of low molecular weight proteins through a normal glomerular barrier. It is most commonly associated with increased free light-chain production in myeloma (Bence Jones proteinuria). It should be suspected if the urine dipstick is negative (dipsticks are albumin specific) when other tests indicate significant proteinuria.

\section{Tubular proteinuria}

Injury to the tubulointerstitial compartment results in the loss both of the proteins that are normally filtered and reabsorbed and of those released by tubular epithelial cells in response to injury. ${ }^{5}$

\section{Orthostatic proteinuria}

Orthostatic proteinuria is a benign condition characterised by proteinuria only when in the upright position. Proteinuria is absent in early morning samples but appears in samples collected later in the day. It is not associated with haematuria, the glomerular filtration rate (GFR) is preserved, and the prognosis is uniformly good. ${ }^{6}$

\section{Glomerular proteinuria}

Glomerular disease causes an increase in the permeability of the glomerular capillary wall to macromolecules (particularly albumin) and results in glomerular proteinuria. It is persistent and may be associated with haematuria and reduced GFR.

\section{Presentation of proteinuric disease}

\section{Asymptomatic proteinuria}

Most patients with proteinuria are asymptomatic and are identified when the urine is tested either as part of the:

- evaluation for some key life event (eg life insurance application, armed forces recruitment), or

- screening process for high-risk individuals (Table 1).

\section{Symptomatic proteinuria}

Nephrotic syndrome. The nephrotic syndrome comprises the following constellation of symptoms:

- heavy proteinuria: above $50 \mathrm{mg} / \mathrm{kg} / \mathrm{day}$ (ie $>3.5 \mathrm{~g} /$ day in a $70 \mathrm{~kg}$ adult)

- hypoalbuminaemia

- oedema

- hyperlipidaemia (and lipiduria).

Patients typically present with oedema, characteristically observed in a periorbital distribution on waking. Progressive oedema then develops with ankle, sacral and genital involvement. Pleural effusions and ascites may also develop. Leukonychia results from hypoalbuminuria, and xanthelasma may also be seen. ${ }^{7}$ Patients with this level of proteinuria may describe frothing of the urine on micturition. The common causes of nephrotic syndrome are shown in Table 2.

Nephritic syndrome. The nephritic syndrome comprises:

- oedema

- hypertension

- proteinuria with significant hematuria

- reduced GFR.

Patients typically present with reduced urine output, and often describe urine as having a smokey or Coca-Cola colour. Ankle oedema is often present but is less marked than in the nephrotic syndrome. Hypertension is usual and may be severe. Nephritic syndrome often occurs

Table 1. Risk factors that prompt screening (including proteinuria testing) for chronic kidney disease (CKD).

- Diabetes

- Hypertension

- Cardiovascular disease (ischaemic heart disease, chronic heart failure, peripheral vascular disease, cerebral vascular disease)

- Structural renal tract disease, renal calculi or prostatic hypertrophy

- Multisystem diseases with potential for kidney involvement (eg systemic lupus erythematosus)

- Family history of stage 5 CKD or hereditary kidney disease 
with evidence of systemic disease (see Table 2). ${ }^{8}$

\section{Evaluation of proteinuria (Fig 1)}

If proteinuria has been detected on a urine dipstick, dipstick testing should be repeated three times to determine whether it is persistent. Trace positivity can be ignored since the dipsticks are very sensitive. The urine should be cultured. For persistent abnormalities, quantification of the proteinuria is necessary.

Table 2. Common causes of nephrotic and nephritic syndromes.

$$
\text { Syndrome }
$$

\begin{tabular}{ll}
\hline \multicolumn{1}{c}{ Nephrotic } & \multicolumn{1}{c}{ Nephritic } \\
\hline Diabetic nephropathy & Post-infectious GN (eg post-streptococcal GN) \\
Membranous nephropathy & IgA nephropathy \\
Minimal change disease & $\begin{array}{l}\text { ANCA-associated vasculitis (eg Wegener's } \\
\text { granulomatosis, microscopic polyarteritis) }\end{array}$ \\
Focal segmental glomerulosclerosis & $\begin{array}{l}\text { Antiglomerular basement membrane disease } \\
\text { (Goodpasture's disease) }\end{array}$ \\
Mesangiocapillary GN & \\
Renal amyloidosis & \\
\hline
\end{tabular}

ANCA = antineutrophil cycloplasmic antibody; GN = glomerulonephritis; lgA = immunoglobulin A.

Current guidelines indicate that when screening high-risk groups for proteinuria, a quantitative measure (see below) is used rather than dipstick testing. ${ }^{9}$

\section{Quantification}

Quantification of proteinuria has historically been performed on 24-hour urine collections; these are inconvenient for patients and therefore inaccurate. Current best practice involves measuring the albumin and/or protein concentration in a 'spot' urine sample (ideally, an early morning sample). ${ }^{10}$

To correct for the effects of urine concentration (hydration state), the albumin/protein concentration is normalised to the creatinine concentration and expressed as the albumin to creatinine ratio (ACR) and protein to

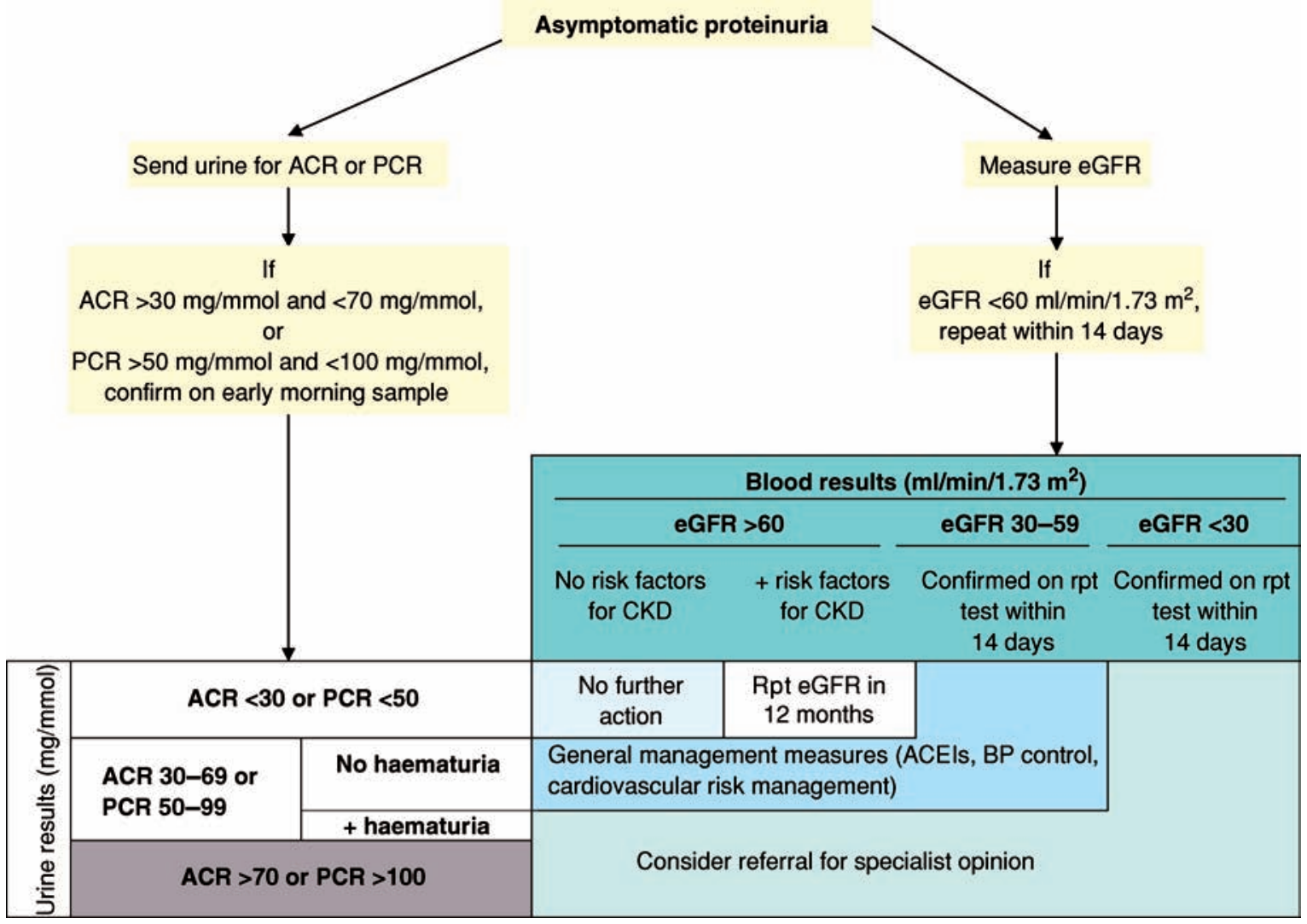

Fig 1. Algorithm for the evaluation of non-diabetic patients with asymptomatic proteinuria. ACEI = angiotensinconverting enzyme inhibitor; $\mathrm{ACR}=$ albumin to creatinine ratio; $\mathrm{BP}=$ blood pressure; $\mathrm{CKD}=$ chronic kidney disease; eGFR = estimated glomerular filtration rate; PCR = protein to creatinine ratio; rpt = repeat. Reproduced with permission from NICE. 
creatinine ratio (PCR), respectively (expressed as $\mathrm{mg}$ albumin or protein/ mmol creatinine). An average person excretes approximately $10 \mathrm{mmol}$ of creatinine per day, so the ACR and PCR can be multiplied by 10 to give an estimate of the daily albumin/protein loss (in mg). The ACR is more sensitive than the PCR, so the former measurement is recommended for the detection and identification of proteinuria while the PCR is reserved for quantification and monitoring.

\section{Excretory renal function}

The excretory renal function should also be determined (plasma creatinine concentration and the calculated estimated GFR (eGFR)). The patient can then be categorised according to their stage of chronic kidney disease (CKD) (Fig 1; Table 3). ${ }^{9}$

\section{Interpreting proteinuria values}

\section{Normal}

Normal protein excretion is less than $150 \mathrm{mg}$ per day - equivalent to a urine PCR of less than $15 \mathrm{mg} / \mathrm{mmol}$.

\section{Nephrotic-range proteinuria}

The nephrotic range of proteinuria is more than $3.5 \mathrm{~g}$ a day (PCR $>350$ $\mathrm{mg} / \mathrm{mmol}$ ). A protein that is predominantly albumin (ie dipstick-positive or high urine ACR) is characteristic of glomerular disease.

\section{Non-nephrotic proteinuria}

A situation in which there is a urine PCR of $15-350 \mathrm{mg} / \mathrm{mmol}$ (ie $150 \mathrm{mg}$ to $3.5 \mathrm{~g}$ of proteinuria per day) is defined as non-nephrotic proteinuria. This can

Table 3. Stages of chronic kidney disease.

eGFR

\begin{tabular}{|c|c|c|}
\hline Stage & $\left(\mathrm{ml} / \mathrm{min} / 1.73 \mathrm{~m}^{2}\right)$ & Description \\
\hline 1 & $>90$ & $\begin{array}{l}\text { Normal or increased GFR with other evidence of kidney } \\
\text { damage (eg proteinuria/haematuria, structural abnormality) }\end{array}$ \\
\hline 2 & $60-89$ & $\begin{array}{l}\text { Slight decrease in GFR with other evidence of kidney } \\
\text { damage (see above) }\end{array}$ \\
\hline $3 A$ & $45-59$ & $\begin{array}{l}\text { Moderate decrease in GFR with or without other evidence } \\
\text { of kidney damage }\end{array}$ \\
\hline 3B & 30-44 & \\
\hline 4 & $15-29$ & $\begin{array}{l}\text { Severe decrease in GFR with or without other evidence of } \\
\text { kidney damage }\end{array}$ \\
\hline 5 & $<15$ & Established renal failure \\
\hline
\end{tabular}

Given the important prognostic role of proteinuria, the suffix $(p)$ can be added to each stage to denote the presence of proteinuria (defined as albumin to creatinine ratio $>30 \mathrm{mg} / \mathrm{mmol}$ or protein to creatinine ratio $>50 \mathrm{mg} / \mathrm{mmol}$ ). eGFR = estimated glomerular filtration rate.

\section{Table 4. Criteria for referral for specialist renal assessment.}

- $\quad$ ACR $>70 \mathrm{mg} / \mathrm{mmol}$ or PCR $>100 \mathrm{mg} / \mathrm{mmol}$ unless known to be due to diabetes and already treated appropriately

- $\quad A C R>30 \mathrm{mg} / \mathrm{mmol}$ or PCR $>50 \mathrm{mg} / \mathrm{mmol}$ when associated with haematuria

- Stage 4 or 5 CKD (with or without diabetes), irrespective of level of proteinuria

- Rapidly declining eGFR ( $>5 \mathrm{ml} / \mathrm{min}$ in 1 year or $>10 \mathrm{ml} / \mathrm{min}$ within 5 years), irrespective of level of proteinuria

$\mathrm{ACR}=$ albumin to creatinine ratio; $\mathrm{CKD}=$ chronic kidney disease; eGFR = estimated glomerular filtration rate; $\mathrm{PCR}=$ protein to creatinine ratio. result from a wide variety of conditions including glomerular disease, nonglomerular parenchymal renal disease and urinary tract disease outside the kidney.

\section{Microalbuminuria}

Microalbuminuria defines an albumin excretion of 30-300 $\mathrm{mg} / \mathrm{day}$. The microalbuminuric range in the urine ACR is $2.5-30 \mathrm{mg} / \mathrm{mmol}$ for men and $3.5-30 \mathrm{mg} / \mathrm{mmol}$ for women. This level is below the detection threshold for conventional dipsticks and is used to identify early diabetic nephropathy. Arguably, it may also be used to assess cardiovascular risk in at-risk populations (eg patients with hypertension).

\section{When to refer to the nephrology service}

The criteria for referral for specialist renal assessment are listed in Table $4 .{ }^{9}$

\section{Key Points}

Proteinuria is a powerful risk factor for the development of progressive renal dysfunction and cardiovascular disease

Measurement of urine albumin to creatinine ratio or protein to creatinine ratio on a 'spot' urine sample has made 24-hour urine collections for proteinuria quantification unnecessary

Screening for proteinuria should be undertaken in patients with risk factors for the development of chronic kidney disease

Early identification of patients with proteinuria offers the best chance of preventing progressive renal dysfunction

Blood pressure control, blockade of the renin-angiotensin system and cardiovascular risk factor management are the key therapeutic goals in proteinuric patients

KEY WORDS: albumin to creatinine ratio, chronic kidney disease, nephrotic syndrome, protein to creatinine ratio, proteinuria 


\section{Management of proteinuria}

The aims of the management of proteinuric patients are to:

- identify the underlying cause and treat where possible

- minimise the risk of renal function deterioration by reducing proteinuria and controlling hypertension

- minimise the risk of cardiovascular disease

- prepare patients with progressive disease for renal replacement therapy.

Patients with nephrotic and nephritic syndromes require specialist renal evaluation. The management of such patients will not be included in this article.

\section{General measures}

Patients should be encouraged to take exercise, achieve a healthy weight and stop smoking. ${ }^{9}$

\section{Blood pressure control and proteinuria reduction}

Non-diabetic patients. The aim in nondiabetic patients is to keep systolic blood pressure below $140 \mathrm{mmHg}$ (target 120-139 $\mathrm{mmHg}$ ) and diastolic below $90 \mathrm{mmHg}$. For those with an ACR above $30 \mathrm{mg} / \mathrm{mmol}$, an angiotensin-converting enzyme inhibitor (ACEI) should be first-line therapy for hypertension. An angiotensin receptor blocker (ARB) may be used if the patient is intolerant of ACEIs. If the ACR is over $70 \mathrm{mg} / \mathrm{mmol}$ (PCR $>100 \mathrm{mg} / \mathrm{mmol}$ ), there is evidence that a combination of an ACEI and ARB provides an additional antiproteinuric and renoprotective effect. ${ }^{11,12}$ Patients with an ACR above $70 \mathrm{mg} / \mathrm{mmol}$ without hypertension also derive renoprotection from combined ACEI and ARB treatment.

Diabetic patients. The threshold for commencing ACEIs/ARBs is lower in patients with diabetes. An ACR above
$2.5 \mathrm{mg} / \mathrm{mmol}$ in men or above 3.5 $\mathrm{mg} / \mathrm{mmol}$ in women justifies the use of ACEIs or ARBs, even in the absence of hypertension.

When used, the dose of either the ACEI or ARB should be increased to the maximum tolerated dose before adding a second agent. For maximum antiproteinuric effect, dietary sodium should be limited to $50-70 \mathrm{mmol} /$ day. About $1-2$ weeks after commencing or increasing the dose of an ACEI or ARB, the serum potassium and eGFR should be checked. If the serum potassium rises to over 6.0 $\mathrm{mmol} / \mathrm{l}$ or the eGFR decreases by more than $25 \%$ from baseline (or plasma creatinine increases by more than 30\%) without any other explanation, the ACEI or ARB should be discontinued.

\section{Cardiovascular risk management}

Cardiovascular disease is the major cause of mortality in patients with proteinuric renal disease so modification of cardiovascular risk is an important treatment goal. ${ }^{13}$ The current recommendations are to use statins for the primary prevention of cardiovascular disease, in the same way as they are used in the general population without CKD, and for secondary prevention of cardiovascular disease, irrespective of baseline lipid values. Low-dose aspirin may be used for secondary prevention of cardiovascular disease. Multiple antiplatelet drugs should be avoided in CKD patients because of an increased bleeding risk. ${ }^{9}$

\section{Conclusions}

Proteinuric disease is a major risk factor for renal failure and cardiovascular morbidity. Early identification of proteinuric patients, aggressive blood pressure control, ACEI/ARB treatment and cardiovascular risk management are key strategies aimed at preventing morbidity and mortality in these high-risk patients.

\section{References}

1 Remuzzi G. Nephropathic nature of proteinuria. Curr Opin Nephrol Hypertens 1999;8:655-63.

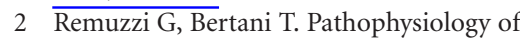
progressive nephropathies. $N$ Engl J Med 1998;339:1448-56.

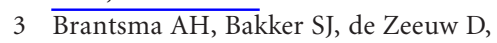
de Jong PE, Gansevoort RT; PREVEND Study Group. Extended prognostic value of urinary albumin excretion for cardiovascular events. J Am Soc Nephrol 2008;19:1785-91.

$4 \overline{\text { Bellinghieri G, Savica V, Santoro D. Renal }}$ alterations during exercise. J Ren Nutr 2008; 18:158-64.

5 Barratt J, Topham P. Urine proteomics: the present and future of measuring urinary protein components in disease. CMAJ 2007;177:361-8.

6 Vehaskari VM. Mechanism of orthostatic proteinuria. Pediatr Nephrol 1990; 4:328-30.

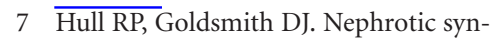
drome in adults. BMJ 2008;336:1185-9.

8 Yoshizawa N. Acute glomerulonephritis. Intern Med 2000;39:687-94.

9 National Institute for Health and Clinical Excellence. Chronic kidney disease. Early identification and management of chronic kidney disease in adults in primary and secondary care. Clinical guideline CG73. London: NICE, 2008. Available at www.nice.org.uk/Guidance/CG73

10 Parsons MP, Newman DJ, Newall RG, Price CP. Validation of a point-of-care assay for the urinary albumin:creatinine ratio. $\mathrm{Clin}$ Chem 1999;45:414-7.

11 Wolf G, Ritz E. Combination therapy with ACE inhibitors and angiotensin II receptor blockers to halt progression of chronic renal disease: pathophysiology and indications. Review. Kidney Int 2005;67:799-812.

12 Cravedi P, Ruggenenti P, Remuzzi G. Intensified inhibition of renin-angiotensin system: a way to improve renal protection? Curr Hypertens Rep 2007;9:430-6.

13 de Zeeuw D. Renal disease: a common and a silent killer. Nat Clin Pract Cardiovasc Med 2008;5(Suppl 1):S27-35.

Address for correspondence:

Dr P Topham, John Walls Renal Unit, University Hospitals of Leicester, Gwendolen Road, Leicester LE5 4PW. Email: peter.topham@uhl-tr.nhs.uk 